ARCHIVO ESPAÑOL DE ARTE, LXXXVIII, 350

ABRIL-JUNIO 2015, pp. 189-197

ISSN: 0004-0428, eISSN: 1988-8511

doi: $10.3989 /$ aearte.2015.12

\title{
VARIA
}

\section{DE LA TRINIDAD ANTROPOMORFA COMO SEDES GRATIAE UNA FUENTE GRÁFICA EN TALLA Y PINTURA: SANTA MARÍA DE VALPUESTA Y EL MUSEO DEL PRADO}

\author{
Jesús María González de Zárate \\ Universidad del País Vasco
}

\begin{abstract}
Pocas representaciones nos han llegado sobre la Trinidad antropomorfa. El presente comentario repara en dos ejemplos del siglo XV: una talla en la colegiata de Valpuesta (Burgos, sede episcopal más antigua de Castilla) y una pintura de Miguel Ximénez custodiada en el Museo del Prado. En el análisis reparamos en la fuente gráfica como invención y modelo que interpretaron tanto el imaginero como el artista pintor.

Palabras clave: Trinidad antropomorfa; Valpuesta; Miguel Ximénez; Iconografía.
\end{abstract}

\section{ON THE ANTHROPOMORPHIC TRINITY AS SEDES GRATIAE. A GRAPHIC SOURCE IN SCULP- TURE \& PAINTING: SANTA MARÍA DE VALPUESTA \& PRADO MUSEUM}

\begin{abstract}
Very few representations of the Anthropomorphic Trinity exist. This commentary focuses on two 15th Century examples: a wood carving in the collegiate church of Valpuesta (Burgos, the oldest episcopal see in Castile), and a painting by Miguel Ximénez in the Prado Museum. The análisis focuses on the graphic source used as a model by both sculptor and painter.

Key words: Anthropomorphic Trinity; Valpuesta; Miguel Ximénez; Iconography.
\end{abstract}

\section{A modo de introducción: Santa María de Valpuesta}

Santa María de Valpuesta fue una fundación que, según se recoge en la historia y nos escribe Enrique Florez en su España Sagrada, se inició allá por el año 804 cuando el rey astur Alfonso II el casto otorgó escritura al obispo Juan. El desarrollo en la reconquista por parte del reino Astur, estableció en este lugar - un pequeño valle (Vallis-Posita)- al obispo Juan. Garibay dio cuenta de la escritura de Fundación que recoge Florez:

Yo Don Alfonso por la gracia de Dios, Rey de Oviedo, Por el amor de Dios, y por el perdón de mis pecados, y por las animas de mis padres, hago privilegio por Testamento con consejo y consentimiento de mis Condes y Príncipes a la Iglesia de Santa María de Valpuesta, y a tí el Venerable Juan, Obispo y Maestro mío, así de las cosas ganadas de la misma Iglesia, como de las de tus antecesores pudo haber adquirido. 
Juan de Mariana en su Historia de España comentaba en el siglo XVI este documento. Repara en una curiosidad al decir que fue dado en santa María de Valpuesta "que hoy es iglesia colegial y antiguamente era monasterio de monja"1.

A través del escrito se deduce una construcción anterior a la llegada del obispo Juan, se trataría de una pequeña fábrica prerrománica de la que habla Florez, dedicada a santa María, y a la que su primer obispo añadió un monasterio. El templo presenta, en consecuencia, una clara evolución y, de su primitiva estructura, se levantó la iglesia románica construida entre los siglos XI y XII por parte de su primer arcediano Don Domingo. Sobre ella, en el siglo XIV, la actual construcción gótica ${ }^{2}$.

La sede episcopal de Valpuesta tuvo varios obispos, Juan, Diego, Felmirio, Diego II, Diego III, Marino, Blas, García, Atton y Antonio, momento en el que Valpuesta pasa al obispado de Nájera (1052-1064). En 1064, Nuño vuelve a ser obispo de Valpuesta y tras unos años bajo el dominio del obispado de Oca en el reinado de Alfonso VI, en el 1090, se convirtió en un arcedianato, es decir, unos dominios que se encontraban bajo la jurisdicción del arcediano, pero dependiente del obispado de Burgos. Florez precisaba en el año 1771:

Acaba aquí la Sede de Valpuesta, que adelante no vuelve a tener Obispo consagrado a su título, sino con el de Burgos, en cuya santa Iglesia fue incorporada la presente, y gobernada por ellos, quedando Valpuesta reducida a Colegiata, Arcedianato de Burgos, como hasta hoy se persevera ${ }^{3}$

Notables personalidades gozaron de esta distinción como arcedianos de Valpuesta pues era sin duda el primero y más distinguido de Castilla. A fines del siglo XV y comienzos del siglo XVI cabe destacar a Rodrigo Borja (1473) -futuro papa Alejandro VI-; Antonio Osorio de Acuña (1495) que fuera obispo de Zamora, asesinado a garrote vil en Simancas por orden de Carlos V; Amadeo de Labrit (1510), hermano del rey navarro Juan de Albret, que fuera nombrado cardenal en la fecha señalada; el también futuro pontífice Adriano de Utrecht (Adriano VI) (1515) y diferentes miembros de una singular familia castellana, los Velasco.

El arcedianato de Valpuesta tuvo gran importancia en la sede episcopal de Burgos. Florez repara en ello en su España Sagrada (tomo XXVI) al precisar que disponía de los puestos más próximos a la silla episcopal. Así, al lado derecho del obispo se encontraban el Deán de la catedral, el chantre y en tercer lugar el Arcediano de Valpuesta pues esta distinción se justificaba en que fue Valpuesta la primera sede episcopal burgalesa en los inicios de la reconquista y, por lo tanto, donde se asentó el primer obispo de Castilla.

El breve comentario sobre Santa María de Valpuesta no quiere olvidar el singular retablo que se da cita en este conjunto, se trata del apostolado en talla que realizara Felipe de Bigarny. Sus figuras, insertas en una mazonería posterior, se levantan sobre la predella con escenas de la vida de María, entalladuras con una claro precedente italiano como hemos tenido ocasión de estudiar en base a los modelos gráficos.

\section{Una talla singular: La Trinidad en su variante Sedes Gratiae (Compassio Patris)}

No es propósito en este comentario considerar las diferentes representaciones de la Trinidad a lo largo de la historia, bien en sus variantes antropomorfa, tricéfala, trifonte o geométrica; tampoco sus disposiciones verticales u horizontales como analiza Didron ${ }^{4}$. Nos centraremos en el análisis de una talla singular del siglo XV o comienzos del XVI que, por su disposición iconográfica, se presenta como uno de los raros y escasos ejemplos que podemos encontrar en el arte sacro tanto

\footnotetext{
${ }^{1}$ Mariana, 1848: 337.

2 Florez, 1781: T. XXVI.

${ }^{3}$ Florez, 1781: T. XXVI.

${ }^{4}$ Didron, 1843: 513-580.
} 


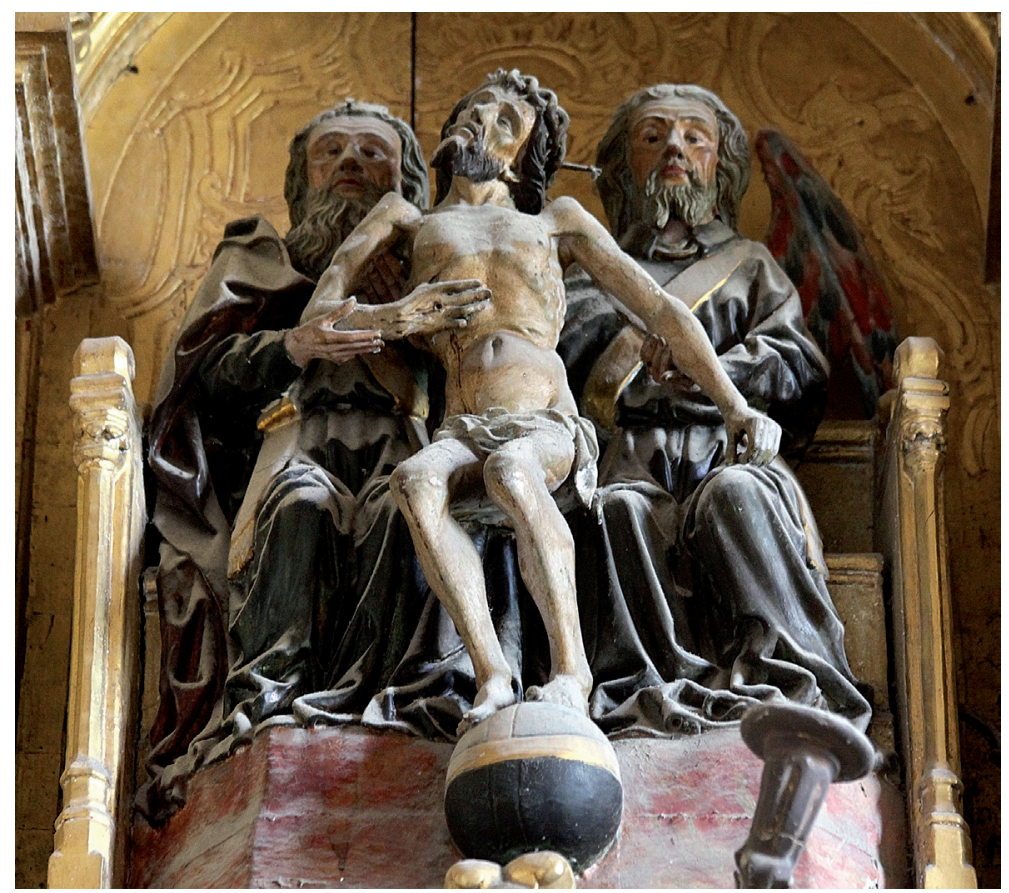

Fig. 1. Trinidad.

Santa María de Valpuesta (Burgos), siglos XV-XVI.

peninsular como europeo. Por otra parte daremos cuenta de una tabla que, por las mismas fechas, compuso el artista pintor Miguel Ximénez y que se conserva en el Museo del Prado.

Tradicionalmente y a partir del siglo XII, las tres personas divinas, quedan representadas a través de Dios Padre como anciano venerable, Dios Hijo como un varón de 33 años ya que se manifestó como hombre mortal y falleció con esa edad y el Espíritu Santo a modo de paloma.

Esta figuración de Dios Padre arranca a partir del siglo IX, perdura en el tiempo y justifica su recreación como un anciano siguiendo al profeta Daniel $(7,9)$ :

Estuve mirando hasta que fueron puestos tronos, y se sentó un Anciano de días, cuyo vestido era blanco como la nieve, y el pelo de su cabeza como lana limpia; su trono llama de fuego, y las ruedas del mismo, fuego ardiente.

Juan, al considerar el bautismo de Cristo, relató la figuración del Espíritu Santo, y nos dice que no es una paloma, sino que apareció como una paloma $(1,30)$ :

He visto al Espíritu bajar del cielo como paloma...

Louis Réau repara en la disposición antropomorfa del dogma trinitario y establece su tipología al considerar la figuración de las tres personas. Considera las miniaturas del Hortus Deliciarum donde la monja Herrade en el siglo XII compuso la Trinidad mediante tres personas que, recordando sin duda la visión de Abraham en Mambré, sentadas una junto a otra, son semejantes. Añade, en un segundo comentario, que ya en el siglo XIV se recrea con la semejanza entre el Padre y el Hijo, apareciendo el Santo Espíritu bajo la conocida forma de paloma. En el tercero de sus ejemplos la Trinidad se recrea mediante tres personas diferentes donde el Espíritu Santo bien toma forma humana o de paloma.

La imagen que comentamos de Valpuesta no responde a estas pautas iconográficas. Observamos que el rostro de Dios Padre, barbado a manera de anciano venerable, se corresponde con el del Espíritu Santo, siendo en consecuencia, semejantes. Dios Hijo, tras su muerte, queda figurado sobre la esfera terrestre, en su desnudez y con los estigmas (fig. 1).

Arch. esp. arte, LXXXVIII, 350, ABRIL-JUNIO 2015, 189-197

ISSN: 0004-0428, eISSN: 1988-8511, doi: 10.3989/aearte.2015.12 
Conocida fue la representación de la Trinidad como Trono de Gracia, es decir, recreando al Padre en su trono sosteniendo a Cristo crucificado y la paloma entre ambos. El origen de esta composición que tanto desarrollo tuvo en el arte se ha de buscar en las representaciones que el abad Suger dispuso para el templo de Saint Denis en el siglo XII donde, si bien queda ausente la señalada paloma, el esquema supone una clara inauguración de este argumento visual que tanto desarrollo tendrá en las artes de los siglo XIII al XVI .

La talla no presenta cruz alguna, en ella podemos contemplar a Dios Padre y al Espíritu Santo barbados y ancianos y con una clara isocefalia, pues son muy semejantes, aspecto claramente novedoso en la iconografía trinitaria. Entre ambos, Cristo muerto con los estigmas de su pasión. Sin duda el argumento parece representar más bien la piedad del Padre con el Hijo. Cristo se presenta sobre la esfera terrestre estableciendo con ello el signo de la Gracia redentora, el cuerpo de Cristo que se ofreció a toda la humanidad.

Réau aclara esta disposición. Nos dice que a partir del siglo XIII se desarrolla en Francia la figuración de Cristo crucificado o con sus estigmas sobre las rodillas del Padre, es la llamada Sedes Gratiae que también se conoce como Compassio Patris, denominación que no encontramos en Didron, tampoco en Crosnier ni en Louis Réau y que viene señalada por Gertrud Schiller en su Iconography of Cristian Art (vol. 2). Claudia Bolgia señala a esta composición como Paternitas y considera su origen, como precisa Dile, claramente bizantino inspirado en las imágenes Theotokos ${ }^{6}$.

Podemos considerar que la talla de Valpuesta se ajusta a este modelo: Sedes Gratiae, aunque plantea algunas diferencias ya que Cristo, con sus estigmas, reposa sobre la esfera entre el Padre y del Espíritu Santo.

Por lo general, sobre el sagrado grupo del Padre y el Hijo muerto, se disponía al Espíritu Santo en la conocida imagen de la paloma. Los ejemplos en la estampa y pintura fueron muy difundidos, a modo de ejemplo podemos reparar en el maestro de la Pasión de Berlín, el monogramista ES, el maestro de Flemalle, Alberto Durero, maestros flamencos anónimos o en el italiano Giorgio Ghisi, sin olvidar la composición del Greco tomando como modelo al ya citado maestro de Nuremberg.

Entre las curiosidades en la talla de Valpuesta hemos precisado la isocefalia del Padre y del Espíritu Santo a quien se le figura alado resaltando con ello su esencia espiritual como Dios de la inteligencia ${ }^{7}$. Con ello se establece una clara distinción entre las tres personas, pues si bien los estigmas definen la imagen de Cristo, las alas conforman al Espíritu Santo. En este sentido el valor de la composición como testimonio iconográfico no es desdeñable.

Didron nos dice que en la figuración antropomorfa el Espíritu Santo suele recrearse como un adolescente $^{8}$, también con la misma edad que Cristo, pero es en el siglo XV y comienzos del XVI cuando suele tomar la misma disposición del Padre a manera de anciano y barbado, como es el caso de la talla que analizamos?.

Entre los teólogos, especialmente en el concilio de Trento, fue un claro tema de discusión la figuración antropomorfa de la Trinidad aceptándose con clara generalidad la recreación de la Tercera Persona a modo de paloma como se relata en el evangelio. Así, a partir del siglo XVI el esquema de

\footnotetext{
${ }^{5}$ Réau, 1996: T. I., V. I., 48.

${ }^{6}$ Bolgia, 2012: 89 .

7 Didron, 1843a: 419.

${ }^{8}$ Pocos son los ejemplos que disponemos en España de la Trinidad antropomorfa realizados en el siglo XV. Uno lo apreciamos en el retablo de la cartuja de Miraflores que realizara Gil de Siloe en el siglo XV donde en la Trinidad antropomorfa el Espíritu Santo queda representado como adolescente. Otro, en la Trinidad del retablo sobre el sepulcro del marques de Villaespesa en Tudela hacia 1460, presenta en la zona superior a la Santísima Trinidad mediante tres cabezas barbudas fundidas en un único ropaje.

${ }^{9}$ Didron, 1843b: 483. Precisa que el Espíritu Santo suele representarse como un niño en el siglo XI, con unos diez a quince años en el XII, adolescente entre quince y veinte años en el XIII, como joven en el XIV, entre treinta y cincuenta años en el XV y como un anciano en el siglo XVI.
}

Arch. esp. arte, LXXXVIII, 350, ABRIL-JUNIO 2015, 189-197 ISSN: 0004-0428, eISSN: 1988-8511, doi: 10.3989/aearte.2015.12 
Dios Padre a manera de anciano venerable, el Hijo en la cruz o desclavado y la paloma como referencia al Espíritu Santo, será la fórmula aceptada por los teólogos y, en consecuencia, por el arte.

La Trinidad antropomorfa favorecía la herejía triteísta y, por tanto, fuera de la ortodoxia; predicaba que la Trinidad son tres seres separados que componen a su vez tres dioses. El planteamiento no se ajustaba al dogma que establece la existencia de un solo Dios en tres personas. Así, la paloma, a modo de símbolo, establecía un mejor y más claro nexo entre el Padre y el Hijo pues, por otra parte, sus figuras quedaban relatadas en el mensaje bíblico ${ }^{10}$.

En consecuencia, la disposición de la Trinidad en tres personas recreadas sobre un banco o trono, daba pié a una diferenciación entre ellas, aspecto que en Trento, como se ha señalado, se consideró podría llevar al equívoco en el dogma cristiano. Sin duda, aquí encontramos la razón de su pronta desaparición en las artes ${ }^{11}$.

\section{La Sedes Gratiae de Valpuesta y del Museo del Prado en su modelo iconográfico}

Las características de la talla que comentamos la convierten iconográficamente en un modelo poco usual en las artes. Podemos reparar en algún ejemplo pictórico del siglo XV que localizamos en la península. $\mathrm{Al}$ respecto damos cuenta de Miguel Ximénez, pintor de Fernando el Católico, que entre los años 148090 compuso la Trinidad sobre tabla (Museo del Prado) (fig. 2).

Gaya Nuño identificó esta pintura en la colección Lanckoronsky de Viena de donde pasó a una colección particular en Nueva York, siendo adquirida por el Estado y depositada en el Museo del Prado en el año $1982^{12}$.

En la tabla, como en Valpuesta, se presenta a Cristo con los estigmas entre el Padre y el Espíritu Santo que lo toman entre sus manos. Cristo, de igual modo, se dispone sobre la esfera terrestre como imagen de la señalada Gracia redentora. La identidad entre los tres rostros parece

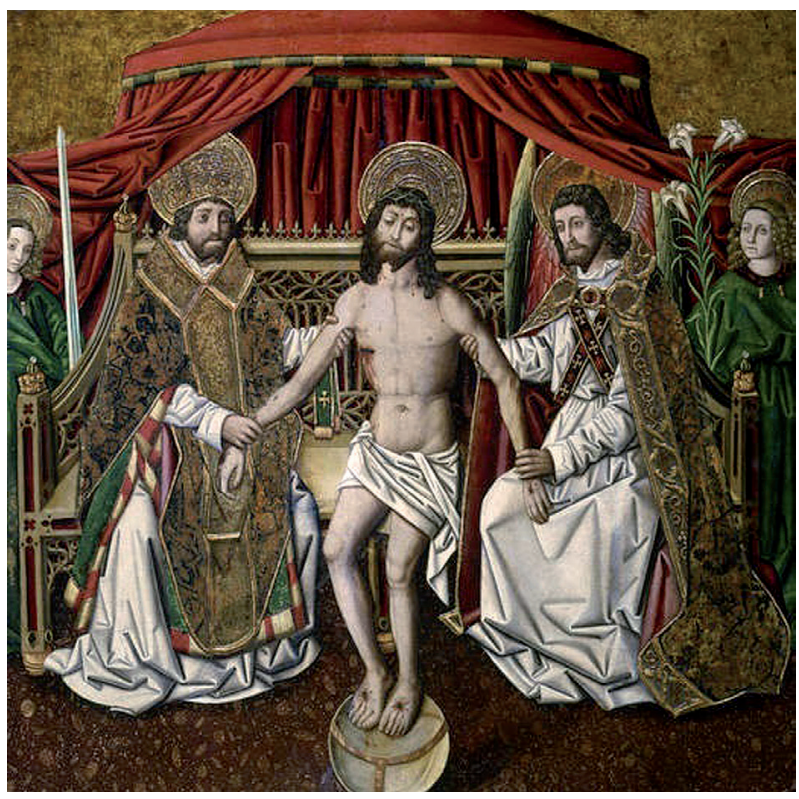

Fig. 2. Trinidad. Miguel Ximénez. Museo del Prado siglo XV. manifiesta y, al igual que en Valpuesta, el Espíritu Santo se dispone alado.

El modelo, en consecuencia, no dista mucho de la escultura, si bien en la talla tanto el Padre como el Espíritu Santo se recrean más ancianos y no presentan vestidura litúrgica. Los brazos de Cristo tienen una movilidad más acentuada y ninguna figura queda coronada como apreciamos en la tabla. Los rostros del Padre y Espíritu Santo son semejantes, no ocurre lo mismo con la figura de Cristo que se dispone con negra barba y más joven.

\footnotetext{
${ }^{10}$ Réau, 1996: T.I., V.I., p. 47.

${ }^{11}$ Kovasc, 1992: 41-58.

12 Gaya Nuño, 1958: 214.
}

Arch. esp. arte, LXXXVIII, 350, ABRIL-JUNIO 2015, 189-197

ISSN: 0004-0428, eISSN: 1988-8511, doi: 10.3989/aearte.2015.12 
Hemos señalado que tanto el modelo de Valpuesta como la pintura conservada en el Museo del Prado, no es muy común en las artes pictóricas y escultóricas. En este sentido, es en el arte gráfico donde podemos considerar la fuente más directa en la elaboración de ambas composiciones.

Un Misal al uso de Roma que fuera ilustrado con una entalladura historiada y coloreada se relaciona claramente con ambas realizaciones artísticas de las que vamos dando cuenta. El libro religioso fue editado en la ciudad holandesa de Gouda por los conocidos Hermanos de la Vida en Común (Fraterheren o Collatiebroeders), asociación de clérigos y laicos dentro de la denominada Devotio Moderna que tanta difusión tuvo en los Países Bajos en la Baja Edad Media. Esta asociación predicaba una reforma espiritual centrada en la vida interior, el conocimiento de las escrituras y una vivencia en función del antiguo cristianismo. Sus ideas tuvieron amplio eco tanto en la Reforma como en la Contrarreforma. Entre sus seguidores se ha de destacar la figura de Kempis y de Erasmo, entre otros.

La fuente gráfica para ambas composiciones que comentamos la podemos encontrar en una inicial historiada en vitela que se da cita en el señalado Misal y que fuera editado entre 1460-80 en la Holanda meridional. Se trata de la inicial "T" del canon de la Misa, su comienzo, -te igitur, por tanto a ti (Dios Padre)-, en entalladura coloreada como se ha precisado y donde se presenta la Trinidad antropomorfa como Sedes Gratiae (fol. 102r) (H.P. Kraus, Nueva York -cat.108, n. 60, pls. XXIV, XXV, 1964) (fig. 3).

Reparando en la pintura de Miguel Ximénez, elaborada entre 1480-90, observamos que tanto los nimbos como la tiara de Dios Padre, las alas en el Espíritu Santo y las vestimentas litúrgicas (estola-palio en x en el Espíritu Santo, como también apreciamos en la talla) presentan una clara semejanza, al igual que los rostros representados. Los brazos extendidos de Cristo se diferencian de esta fuente gráfica. En consecuencia, la pintura interpreta con claridad la estampa que proponemos.

No obstante, el estudio de la pintura por Rosa Donoso Guerrero propone otra fuente gráfica, nos dice: El tema se ha extraído, con variantes, de un grabado de Israel van Meckenem el Viejo, también conocido como Maestro de la Pasión de Berlín (1450-65) (fig. 4). Precisa que se dan cita algunas diferencias. Señala, como hemos apuntado, que el argumento es raro en las artes: Iconográficamente, existen otras diferencias entre el grabado y nuestra tabla; mientras que en el grabado, Dios Padre está representado como un anciano con larga barba, en el cuadro está concebido más joven y en ambos lleva la tiara; la figura del Hijo, tanto en el grabado como en la tabla, se reconoce por la corona de espinas y las llagas del costado, manos y pies; el Espíritu Santo aparece alado en ambos casos. Es una variante muy rara del tipo trinitario denominado "Compassio Patris", en la que el Espiritu Santo, en figura de ángel y con barba, es asociado al dolor del Padre en la escena de la Piedad ${ }^{13}$.

Como podemos observar, la fuente más directa en la pintura la hemos de localizar en la entalladura del Misal que hemos propuesto, pues la identidad en los rostros es notable, como lo es la disposición de la tiara en Dios Padre y los nimbos en las tres personas presentando a Cristo con la corona de espinas. También la señalada estola en x que observamos en el Espíritu Santo. En el grabado propuesto por Rosa Donoso, vemos la disposición de los dos pies del Hijo sobre la esfera terrestre mientras que en el citado Misal tan solo reposa uno de ellos.

Si nos detenemos en la talla de Valpuesta, el Padre y Espíritu Santo se recrean ancianos y de similar rostro, sin vestimentas litúrgicas destacadas aunque el Padre porta capa y ambas figuras llevan la estola en x. Es en la figura de Cristo, con corona de espinas, donde encontramos su dependencia con el modelo gráfico señalado, el movimiento de sus brazos -uno de ellos alargado-, en sentido inverso, define la fuente de inspiración pues la identidad queda manifiesta. También,

\footnotetext{
${ }^{13}$ Donoso Guerrero, 1987: 461.
} 


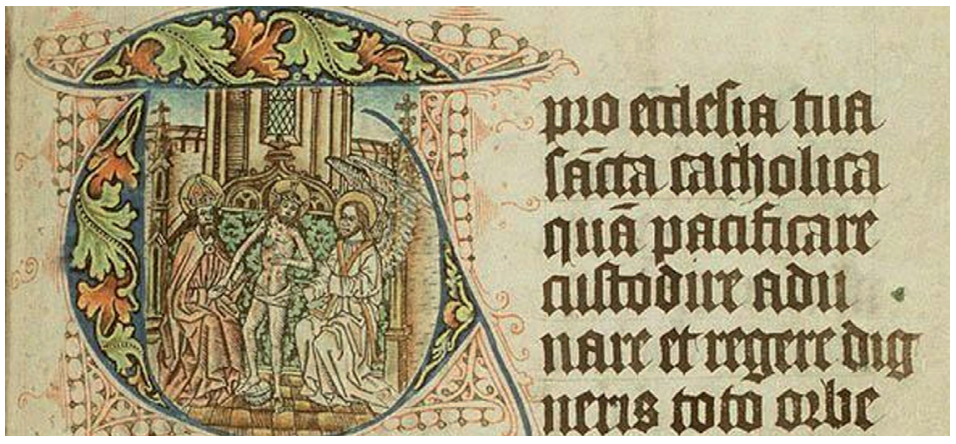

Fig. 3. Trinidad. Entalladura historiada coloreada. Misal holandés, 1460-80.

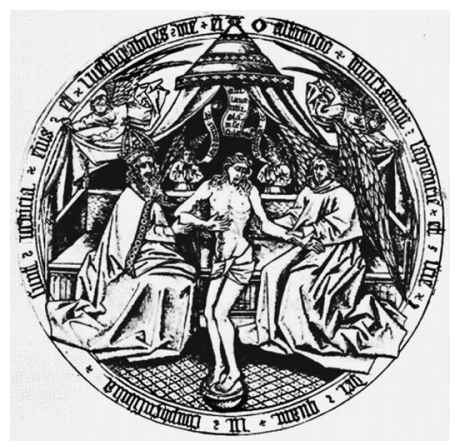

Fig. 4. Trinidad. Entalladura atribuida al Maestro de la Pasión de Berlín (Israel van Meckenem el viejo).

la estola en forma de x se manifiesta en la talla, como la señalada capa de Dios Padre. Por tanto, podemos considerar que la entalladura supuso la fuente iconográfica que fundamenta el argumento visual en ambas representaciones; también para el citado grabado del siglo XV abierto por el llamado maestro de la Pasión de Berlín por Lehrs (1889) pues, de igual manera circular, interpreta con ligeras variaciones una misma iconografía ${ }^{14}$.

Sobre el particular se ha de precisar que el citado maestro de la Pasión de Berlín, fue un grabador de quien no podemos precisar su origen ya que se postulan dos lugares: Alemania y Holanda. Es sabido, como estudia Ursula Weekes, que su producción personal y la de su taller se centró, entre los años 1450-1500, en la ilustración de manuscritos, especialmente libros devocionales con entalladuras coloreadas en la zona entre el Mosa y el Rin, es decir, en la Holanda meridional donde fue editado hacia 1460 el Misal que vamos señalando ${ }^{15}$. En consecuencia, por la proximidad geográfica y cronológica, por la identidad iconográfica entre la entalladura del Misal y la estampa suelta en un argumento tan particular como lo fue la Trinidad antropomorfa, no se puede descartar bien la participación del maestro de la Pasión o la de su taller en el citado Misal de Gouda.

Kraus, considerando la entalladura del Misal precisa que es uno de los primeros ejemplos en la historia donde apreciamos el grabado, la entalladura, ilustrando la página de un libro manuscrito. Por otra parte, repara en las dos estampas que comentamos, en el Misal y en la abierta por el maestro de la Pasión. Precisa que la entalladura del Misal precede a la estampa del maestro de la Pasión pero entiende que ambas deben su invención a una miniatura como modelo común ${ }^{16}$.

En el libro de horas de Paul van Overtvelt (Brujas 1410-Bruselas 1483), consejero del duque de Borgoña, encontramos una miniatura, tempera sobre pergamino, atribuida a Petrus Christus (ca.1410-1475) [KRB, ms IV 95, fol. $155 \mathrm{v}$ ], se trata de la Trinidad antropomorfa que, como observamos, se encuentra en clara relación con las fuentes gráficas que vamos señalando, especialmente con la estampa del maestro de la Pasión (fig. 5). Un sencillo cambio de lugar entre Dios

${ }^{14}$ González de Zárate, 2000. El libro presenta un análisis sobre los más destacados grabadores de los siglos XV y XVI europeo.

${ }^{15}$ Weekes, 2004.

${ }^{16}$ Kraus, 1964: 44.

Arch. esp. arte, LXXXVIII, 350, ABRIL-JUNIO 2015, 189-197

ISSN: 0004-0428, eISSN: 1988-8511, doi: 10.3989/aearte.2015.12 


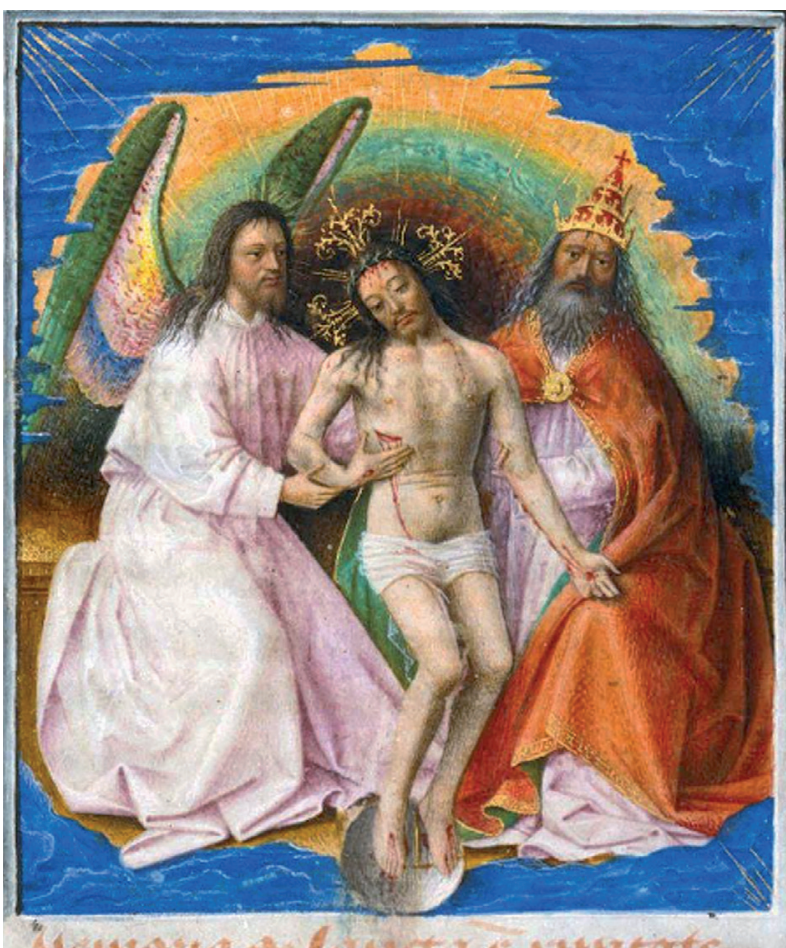

Fig. 5. Trinidad. Libro de Horas de Paul van Overtvelt. Miniatura atribuida a Petrus Christus.

Padre y el Espíritu Santo establecen la diferencia; sus edades, vestimentas y disposición de sus manos es claramente similar ${ }^{17}$. Los brazos de Cristo parecen estar más en consonancia con la citada entalladura del Misal.

En consecuencia, tanto la talla de Valpuesta como la pintura de Miguel Ximénez, interpretan la invención de uno de los tres modelos señalados, todos ellos de la segunda mitad del siglo XV y elaborados en la Holanda meridional. La identidad más próxima la consideramos en el Misal de Gouda, pues la tabla recrea con claridad la figura de Dios Padre y del Espíritu Santo, siendo la imagen de Cristo la que establece una singular dependencia con la talla que comentamos.

\section{Adriano de Utrecht y la Trinidad en Valpuesta}

Reparamos en las singulares personalidades que ocuparon el arcedianato de Valpuesta. Rodrigo Borja alcanzó el pontificado en 1492 siendo arcediano desde 1473; Amadeo Labrit, de la casa real de los Albret, en 1510, siendo posteriormente cardenal. Adriano Florisz Boeyens, más conocido como Adriano de Utrecht, fue Papa (Adriano VI) entre los años 1522-23, siendo arcediano de Valpuesta en el año 1515, fecha en la que el emperador Maximiliano le nombra tutor de su nieto, el futuro Carlos V.

El holandés Adriano destacó por su austeridad, aspecto que le distinguió de los pontífices Médici que anterior y posteriormente ocuparon la silla pontifical, León X y Clemente VII. Su sobriedad no fue positiva para las artes ya que en su periodo vaticano operó una decadencia como muy bien señaló Chastel. Fue su espíritu de reforma lo que motivó su elección en el conclave (sin su asistencia), una llamada de atención ante la sensualidad y vida relajada en la iglesia romana.

La talla que analizamos, de pequeño tamaño, expresa una notable sencillez en su elaboración. Damos cuenta de su fuente gráfica en base a la entalladura de un Misal holandés. Precisamos su edición por parte de los conocidos Hermanos de la Vida en Común y es en esta circunstancia donde podemos considerar la figura de Adriano en Utrecht en relación con la escultura que comentamos.

Adriano, fue en su vida un ejemplo de austeridad y ascetismo. Nació en Utrecht en el seno de una familia modesta. Curiosamente, sus primeros estudios los realizó con los señalados Hermanos de la Vida en Común, posteriormente se doctoró en Lovaina ejerciendo como profesor de teología, destacando entre sus alumnos la figura de Erasmo de Rotterdam.

${ }^{17}$ En la miniatura se dispone a Cristo a la derecha del Padre, no así en las dos entalladuras que presentamos. Por tanto, se ajusta más a la fuente bíblica donde se señala que Cristo resucitó y se sentó a la derecha del Padre. Salmos 110,1; Mateo 26,64; Hechos 2,55,56; Efesios 1,20; Colosenses 3,1; Hebreos 1,3; Hebreos 1,13; 1 Pedro 3,22. 
En este sentido, considerando que la Sedes Gratiae fue un modelo iconográfico que se manifestó a finales del siglo XV y comienzos del XVI, que la fuente gráfica se encuentra en un Misal editado en Holanda por los Hermanos de la Vida en Común, asociación religiosa a la que perteneció Adriano de Utrecht, no extraña que la talla fuera propuesta y llegara a la hoy población burgalesa de la mano del por entonces arcediano Adriano de Utrecht ${ }^{18}$.

\section{BIBLIOGRAFÍA}

Bolgia, C. (2012): "The original setting and historical contexto g the fourteenth-century 'Anthopomorphic Trinity' of the museo di Roma at Palazzo Braschi". En: A Wider Trecento: Studies in 13th- and 14thCentury European Art Presented to Julian Gardner, Leiden.

Didron, M. (1843): Iconographie chrétienne. Histoire de Dieu. París.

Dile, A. (1998): The Anthropomorphic Holy Trinity in Byzantine and Post-Byzantine. University of London (Courtauld Institute of Art), Londres.

Donoso Guerrro, R. (1987): “Algunas tablas aragonesas recuperadas por el Estado”. En: Homenaje a D. Federico Balaguer Sánchez.

Florez, E. (1771): España Sagrada, Madrid: T. XXVI.

Gaya Nuño, J. A. (1958): La pintura española fuera de España, Madrid.

Kovacs, Z. (1992): "Trinitas in hominis specie. Quelques remarques à propos de l'iconographie des representations anthropomorphes de la Trinitè". Bulletin du Musée Hongrois des Beaux-Arts 77, pp. 41-58.

Kraus, H.P. (1964): (ed.) The Illustrated Book: Illuminated Manuscripts; Early Woodcut Books ... Index of Illuminators, Illustrators, \& Engravers, Nueva York.

Mariana, J. (1848): Historia General de España, Madrid.

Réau, L. (1996): Iconografia del arte cristiano. Iconografia de la Biblia. Antiguo Testamento. Barcelona. VV.AA. (1987): Nueva Historia de la Iglesia, T. II. Madrid.

Weekes, U. (2004): Early Engravers and their Public: The Master of the Berlin Passion and Manuscripts from Convents in the Rhine-Maas Region, ca. 1450-1500 (Studies in Medieval and Early Renaissance Art History), Londres.

Fecha de recepción: 24-VII-2014

Fecha de aceptación: 09-II-2015

${ }^{18}$ VV.AA., 1987:160.

Arch. esp. arte, LXXXVIII, 350, ABRIL-JUNIO 2015, 189-197

ISSN: 0004-0428, eISSN: 1988-8511, doi: 10.3989/aearte.2015.12 